\title{
A FORMAÇÃO DE COORDENADORES PEDAGÓGICOS: PRÁTICAS E NECESSIDADES FORMATIVAS EM DISCUSSÃO
}

\section{PEDAGOGICAL COORDINATORS' EDUCATION: PRACTICE AND FORMATIVE NEEDS IN DISCUSSION}

\author{
Andreia Cristiane de Oliveira ${ }^{1}$ \\ Simone Albuquerque da Rocha ${ }^{2}$ \\ Jéssica Lorrayne Ananias da Silva ${ }^{3}$
}

\begin{abstract}
Resumo
Este texto resulta de uma investigação realizada com o objetivo de mapear e analisar as produções, em âmbito nacional, que abordem a coordenação pedagógica, com um recorte para as pesquisas que contemplem a formação dos coordenadores pedagógicos nos contextos escolares. Parte-se do entendimento de que as iniciativas e propostas de formação para coordenadores pedagógicos devem estar alinhadas às suas necessidades formativas para que ocorra a significação desta formação nas ações pedagógicas do coordenador. Para atender ao objetivo da pesquisa foram mapeadas teses de doutorado e dissertações de mestrado no catálogo de teses e dissertações da Coordenação de Aperfeiçoamento de Pessoal de Nível Superior do Ministério da Educação (CAPES/MEC) e no site da Biblioteca Digital Brasileira de Teses e Dissertações (BDTD) do Ministério de Ciência e Tecnologia (MCT), considerando o recorte temporal de 2008 a 2018, e buscou-se investigar: O que revelam as pesquisas com relação às necessidades formativas dos coordenadores pedagógicos? Em que medida as propostas e iniciativas de formação continuada direcionadas aos coordenadores pedagógicos e referenciadas nas pesquisas mapeadas têm refletido nas ações pedagógicas por eles desenvolvidas? A investigação possibilitou depreender que, ainda que as pesquisas sobre a temática tenham avançado consideravelmente nos últimos anos, são incipientes as iniciativas de formação continuada que considerem as necessidades formativas dos coordenadores pedagógicos como balizadoras da sua formulação e realização, favorecendo assim, o distanciamento entre o proposto nas pesquisas e o que tem se observado na atuação dos coordenadores.
\end{abstract}

Palavras-chave: Coordenadores Pedagógicos; Formação Continuada; Necessidades Formativas.

\footnotetext{
Abstract

This text is a result of an investigation developed with the objective of mapping and analyzing the productions, in national scope, that covers the pedagogical coordination, with an approach to the researches that considers the coordinators' education into the schools' context. It comes

1 Mestre em Educação (UFMT); Professora da rede pública estadual do Mato Grosso (SEDUC/MT); Rondonópolis, Mato Grosso; E-mail:andreia.prof.cristiane@outlook.com

2 Doutora em Educação (UNESP/SP); Professora Associada da Universidade Federal de Rondonópolis (UFR); Rondonópolis, Mato Grosso; E-mail: as.rocha@terra.com.br.

3 Mestranda do Programa de Mestrado em Educação (PPGEdu/UFMT) Professora da rede pública municipal de Rondonópolis; Rondonópolis, Mato Grosso. E-mail: jessicasilva_jeh@ hotmail.com.
} 


\section{OO DEVIR EDUCAÇÃO \\ ISSN: 2526-849X}

from the understanding of both initiative and proposals of teacher education to the pedagogical coordinators must be aligned to their education needs in order to occur the significance of this teacher education in the pedagogical coordinator's actions. In order to contemplate the aim of this research, a mapping of doctoral thesis and masters' dissertations were developed based on the catalogue of thesis and dissertations from the Coordenação de Aperfeiçoamento de Pessoal de Nível Superior do Ministério da Educação (CAPES/MEC) and in the site of the Biblioteca Digital Brasileira de Teses e Dissertações (BDTD) do Ministério de Ciência e Tecnologia (MCT), considering a temporal period from 2008 to 2018, with the intention of investigating: what do the researches reveal in relation to the pedagogical coordinators' educational needs? In which proportion do the proposals and initiatives of continuing teacher education directed to the pedagogical coordinators and referenced in the mapped researches have reflected upon the pedagogical actions developed by them? It was possible to find in the research that even if the thematic has moved forward considerably in the late years, it is yet novice the initiative of the continuing teacher education that considers the pedagogical coordinators' educational needs as baseline of their formulation and realization, thus promoting, the distance between the proposal in the researches and what have been observed in the coordinators' performance.

Keywords: Pedagogical Coordinators; Continuing Teacher's Education; Educational Needs.

\section{Introdução}

A coordenação pedagógica tornou-se um dos temas mais discutidos entre os estudiosos da área educacional a partir da década de 1990. No cerne dessas discussões estão as constantes inovações no campo educacional, que passaram a requerer de professores e demais funcionários das escolas a revisão de concepções, desenvolvimento de competências e a adesão a um movimento que pressupõe o trabalho conjunto dos educadores (ORSOLON, 2002), permeado pelo diálogo entre todos os envolvidos no processo educacional, tendo os coordenadores pedagógicos (CPs) como mediadores dessas ações.

De acordo com o que preconizam Placco, Almeida e Souza (2011), as pesquisas, no campo da educação, que focalizam a coordenação pedagógica revelam principalmente a necessidade de compreender suas atribuições e práticas e, ao mesmo tempo, fundamentar princípios para as ações do coordenador. Essas pesquisas situam os CPs como os principais responsáveis pela formação continuada.

À dimensão formadora, agregam-se as dimensões articuladora e transformadora, que constituem a natureza da sua atuação. Circunscrevem-se, nessas dimensões, o acompanhamento à proposta pedagógica da escola, expressa no Projeto Político Pedagógico, o direcionamento da equipe docente com relação aos aspectos metodológicos, o planejamento, a avaliação, e o aprofundamento das teorias pedagógicas e do conhecimento acerca das diretrizes educacionais.

Revista Devir Educação, Lavras, vol.4, n.1, p.26-46 jan./jun., 2020. 


\section{QD DEVIR EDUCAÇÃO \\ ISSN: 2526-849X}

Soma-se ao fazer pedagógico dos coordenadores a necessidade de organização do coletivo da escola, visando o desenvolvimento de ações que impliquem na execução do projeto institucional, superando as ações isoladas da equipe gestora e equipe docente.

Considerando-se a natureza do trabalho do coordenador pedagógico e a multidimensionalidade de sua atuação, torna-se necessário realizar o trabalho coletivo integrado aos atores educacionais, com vistas à mediação da competência docente, que pressupõe professores cientes de sua atuação e de suas necessidades formativas, e, a partir disso, investir na formação continuada do professor na escola, transformando a dimensão formativa no núcleo de sua ação coordenadora.

Diante do contexto das funções dos CPs, salienta-se a necessidade de que, para atender ao disposto em suas atribuições, eles necessitam, como parte do seu desenvolvimento profissional, acrescentar aos seus saberes docentes as habilidades e as competências próprias para o exercício da função. Ao analisarmos a atuação do CP devemos nos atentar ao fato de que ele é, a priori, um professor que exerce a função de coordenador e conforme afirma Placco (1994, p.18) “que traz subjacente um saber fazer, um saber ser e um saber agir”.

Alves (2007, p.228-229) pondera que a aprendizagem da função de coordenador pedagógico se sustenta nas experiências e nos desafios do cotidiano. Entretanto, aponta para uma desarticulação entre a teoria e a prática "[...] indicando um distanciamento entre os conteúdos aprendidos na formação acadêmica e os saberes requisitados no trabalho cotidiano". Esta deficiência na formação inicial e continuada dos coordenadores é apontada por Miziara, Ribeiro e Bezerra (2014) como um dos elementos que potencializam o sentimento de fragilidade que os coordenadores enfrentam, face aos desafios do exercício da função.

As autoras expõem que um dado evidenciado nas pesquisas sobre a coordenação pedagógica refere-se à

[...] deficiência da formação inicial dos coordenadores no que tange a aspectos metodológicos, planejamento, gestão escolar, conhecimento das teorias pedagógicas, avaliação educacional e da aprendizagem, currículo e formulações de políticas públicas, ou seja, há um divórcio entre teoria e prática. (MIZIARA; RIBEIRO; BEZERRA, 2014, p. 614).

Partimos do entendimento de que os elementos supra citados configuram-se em necessidades formativas dos coordenadores pedagógicos, concebendo-se necessidade formativa de acordo com a proposição de Zabalza (1994, p. 62) ao esclarecer que uma 


\section{QD DEVIR EDUCAÇÃO \\ ISSN: 2526-849X}

necessidade formativa é instituída pela discrepância que se produz "entre a forma como as coisas deveriam ser (exigências), poderiam ser (necessidades de desenvolvimento) ou gostaríamos que fossem (necessidades individualizadas) e a forma como essas coisas são de fato". Segundo o autor, a diferença entre o estado atual de desenvolvimento e o estado desejado, dentre outros fatores, determina as necessidades formativas.

Sublinhado isso, este texto resulta de pesquisa realizada com o objetivo de mapear as produções, em âmbito nacional, que abordem a coordenação pedagógica, com um recorte para as que contemplem a formação dos coordenadores pedagógicos nos contextos escolares.

Para atender ao objetivo da pesquisa, assentada em uma abordagem qualitativa, foram mapeadas 8 teses de doutorado e 53 dissertações de mestrado encontradas nos sites da CAPES ${ }^{4}$ e BDTD ${ }^{5}$, considerando o recorte temporal de 2008 a 2018. Procedeu-se então ao exame dos títulos, resultando em 34 produções selecionadas para análise, sendo 4 teses e 30 dissertações, em que se buscou investigar: o que revelam as pesquisas com relação às necessidades formativas dos coordenadores pedagógicos? Em que medida as propostas e iniciativas de formação continuada direcionadas aos coordenadores pedagógicos e referenciadas nas pesquisas mapeadas têm refletido nas ações pedagógicas por eles desenvolvidas?

Parte-se da compreensão de que as iniciativas e propostas de formação para coordenadores pedagógicos devem estar alinhadas às suas necessidades formativas, para que ocorra a significação desse processo nas ações pedagógicas do coordenador. Assim, intentouse, com este estudo, contribuir para a reflexão acerca desta temática que se configura como componente balizador das ações políticas e pedagógicas dos coordenadores.

\section{Análises temáticas sobre a coordenação pedagógica: considerações e aproximações com base em revisões bibliográficas}

Embora a formação inicial e continuada dos CPs esteja em relevo nas pesquisas nacionais, o seu papel enquanto formador continua em discussão, o que se pode considerar um paradoxo, pois coadunamos com a afirmação de Garcia (2016, p. 11) de que "não é possível pensar em formação dos outros sem ter clareza da formação de si, e não é possível coordenar a ação pedagógica dos outros sem ter perceptibilidade das suas próprias ações”.

\footnotetext{
${ }^{4}$ Coordenação de Aperfeiçoamento de Pessoal de Nível Superior do Ministério da Educação (CAPES/MEC)

${ }^{5}$ Biblioteca Digital Brasileira de Teses e Dissertações (BDTD) do Ministério de Ciência e Tecnologia (MCT
}

Revista Devir Educação, Lavras, vol.4, n.1, p.26-46 jan./jun., 2020. 


\section{QD DEVIR EDUCAÇÃO \\ ISSN: 2526-849X}

Ao problematizar acerca da formação continuada nas escolas e a responsabilidade do CP neste processo, considerando-se que a coordenação pedagógica é exercida por um professor, Placco, Almeida e Souza (2011, p. 235) asseguram que na execução de sua função formativa "saberes específicos são requeridos, além dos saberes da docência, embora ancorados neles, o que reporta à necessidade de novas aprendizagens, tanto para o adulto professor quanto para $\mathrm{o}$ adulto coordenador".

Portanto, nesta parte do texto traremos as pesquisas já socializadas sobre mapeamentos realizados que focalizaram o coordenador pedagógico, tais como as de Geglio (2010), Placco, Almeida e Souza (2011), Miziara, Ribeiro e Bezerra (2014), e em seguida as produções coletadas para este artigo.

\subsection{Contribuições de mapeamentos acerca de produções que abordam a coordenação pedagógica já socializados em pesquisas}

Com base em estudos de Ferreira (2002), André (2005) Romanowski; Ens (2006), Romanowski (2013), é possível afirmar que as pesquisas em educação avançaram consideravelmente nos últimos anos, com múltiplos enfoques e abordagens. Nesse viés, Ferreira (2002, p.14) pontua que, "ainda que seja evidente esse aumento da produtividade nas pesquisas sociais e educacionais [...] não significa, necessariamente, garantia de relevância ou aplicabilidade efetiva para as pesquisas realizadas". A afirmação da autora reflete a inquietação de que os resultados das pesquisas sejam refletidos em ações no sentido da ressignificação das práticas educacionais, bem como na otimização dos processos relativos ao cenário educativo.

Pesquisadores e estudiosos do campo educacional têm intensificado seus estudos acerca da coordenação pedagógica, e assinalam um certo consenso sobre a importância deste profissional nas escolas, bem como a multidimensionalidade da sua atuação. Para fundamentar as discussões acerca das análises temáticas das produções, destacamos como fontes empíricas as pesquisas já realizadas por Geglio (2010), Placco, Almeida e Souza (2011), Miziara, Ribeiro e Bezerra (2014), no intuito de apresentar os dados já mapeados e examinados pelos autores mencionados acerca das produções sobre a coordenação pedagógica em âmbito nacional. Por meio das análises dos referidos textos, buscamos traçar o panorama das pesquisas sobre a coordenação pedagógica ao longo dos últimos anos e destacamos elementos que consideramos imprescindíveis para a presente reflexão.

Revista Devir Educação, Lavras, vol.4, n.1, p.26-46 jan./jun., 2020. 


\section{OO DEVIR EDUCAÇÃO}

ISSN: 2526-849X

O trabalho de Geglio (2010), publicado na Revista Eletrônica Pesquiseduca, consistiu em um levantamento das produções sobre o $\mathrm{CP}$ e na análise temática de teses, dissertações, artigos de periódicos, trabalhos apresentados nas reuniões da ANPEd e livros. A investigação pautou-se no período de 1988 a 2009, com buscas na CAPES, ambiente virtual da ANPEd, editoras, bibliotecas das universidades e do Google.

$\mathrm{O}$ autor apontou 134 produções mapeadas, sendo 123 dissertações e 11 teses de doutorado, que abordam no seu título as expressões "coordenador pedagógico" ou "supervisor pedagógico". Com base nos resumos, considerou sete grupos temáticos, no intuito de identificar os assuntos mais recorrentes nas produções, bem como agrupá-las em função da proximidade dos temas abordados: constituição da função, percurso histórico, identidade do CP; práticas do $\mathrm{CP}$ no contexto escolar; o CP e a formação continuada do professor; a relação do CP com o professor; a formaçao do $\mathrm{CP}$; relações políticas, sociais, de gestão escolar e com as famílias; o CP na visão do professor (GEGLIO,2010).

$\mathrm{O}$ autor concluiu que é baixo o volume de trabalhos sobre o $\mathrm{CP}$, sendo que a maior concentração de trabalhos deu-se nas dissertações de mestrado. Geglio, (2010, p.20) salienta ainda que o enfoque das produções é variado, porém, "faltam investigações abrangentes a respeito do reflexo do trabalho do coordenador pedagógico na prática do professor, assim como pesquisas mais detidas sobre a visão dos professores a respeito da ação do CP em seu trabalho".

No entendimento de Placco, Almeida e Souza (2011), embora o aumento no número de pesquisas com a temática "coordenação pedagógica" seja evidente, ainda permanece o desafio de caracterizar e analisar a atuação deste profissional, considerando-se o contexto e as especificidades das diferentes regiões brasileiras.

Em pesquisa realizada em 2010 pela Fundação Vitor Civita (FVC) e coordenada pelas autoras supra citadas, denominado "O coordenador pedagógico (CP) e a formação de professores: intenções, tensões e contradições", as autoras buscaram identificar e ampliar o conhecimento acerca das funções, potencialidades e limitações dos CPS das escolas de Ensino Fundamental e Médio de diferentes regiões brasileiras, visando elencar subsídios para políticas públicas de formação docente, bem como a organização dos sistemas escolares. Os estudos realizados por Placco, Almeida e Souza foram socializados com a comunidade acadêmica em 2011, em forma de relatório, e, em 2012 e 2016, em periódicos e eventos.

A análise das produções sobre coordenação pedagógica evidenciou um interesse crescente sobre a temática, envolvendo a questão da profissão, da identidade profissional e da carreira, que as autoras categorizaram como perspectivas de investigação mais abrangentes.

Revista Devir Educação, Lavras, vol.4, n.1, p.26-46 jan./jun., 2020. 


\section{OO DEVIR EDUCAÇÃO \\ ISSN: 2526-849X}

Mencionam também abordagens mais focadas no sujeito, como os aspectos subjetivos do CP, suas habilidades e competências.

As autoras avaliam que

No que concerne aos temas, objetivos e questões investigados nessas pesquisas, eles são muitos e variados, contudo, a imensa maioria circunscrevese nos três eixos: [...] articulação dos processos pedagógicos e educativos; transformação das condições pedagógicas e de ensino; formação de professores (PLACCO; ALMEIDA; SOUZA, 2011, p. 236).

Além das teses e dissertações, as autoras fazem menção à literatura existente, analisando textos que discutem o papel e funções dos CPs. Neste sentido, destacam os estudos de Mate (1998) sobre a identidade do CP; Almeida (2000), que defende a importância do CP na ressignificação do trabalho docente; Placco e Souza (2008), que discutem o CP como mediador da coletividade; André e Vieira (2006), que abordam os saberes e aprendizagens do CP; Placco e Souza (2010), que ampliam o entendimento acerca dos saberes do CP ao relacionar a memória, a metacognição e a subjetividade; Cunha e Prado (2008), que discorrem sobre a coformação, defendendo a importância do CP como interlocutor privilegiado entre os professores e o processo reflexivo sobre a prática; e por fim, Bruno (1998), que discute o papel do CP sob diferentes perspectivas.

De acordo com as análises de Placco, Almeida e Souza (2011) acerca das obras e produções examinadas, o ponto em comum é a defesa de que o $\mathrm{CP}$ é o principal responsável pela formaçao continuada dos professores. Além disso, os textos referenciados sugerem que

[...] as atribuições do coordenador, no que se refere à dimensão formativa, se fundamentam em: promover a articulação da equipe escolar para elaborar o projeto político-pedagógico da escola; mediar as relações interpessoais; planejar, organizar e conduzir as reuniões pedagógicas; enfrentar as relações de poder desencadeadas na escola; desempenhar sua prática atendendo à diversidade dos professores e das escolas; efetivar o registro escrito como forma de sustentar a autoria de seu papel na escola. (PLACCO; ALMEIDA; SOUZA, 2011, p. 235).

À luz das proposições teóricas que embasaram a investigação das autoras, reconhece-se o papel central do coordenador pedagógico nas ações que se desenvolvem nos espaços escolares, bem como a importância de que este profissional desenvolva saberes e competências que o habilitem para o exercício da função.

Revista Devir Educação, Lavras, vol.4, n.1, p.26-46 jan./jun., 2020. 


\section{OO DEVIR EDUCAÇÃO \\ ISSN: 2526-849X}

A publicação de Miziara, Ribeiro e Bezerra (2014) tem como assunto o levantamento bibliográfico sobre a atuação do coordenador pedagógico e o papel que ele desempenha no contexto escolar. Os autores procederam a busca no portal da CAPES e no site Domínio Público, BDTD e Google Acadêmico, com o recorte temporal de 2000 a 2012, utilizando os descritores: coordenador pedagógico, professor coordenador, supervisor escolar e coordenador de área.

Dos 196 trabalhos localizados pelos pesquisadores, foram selecionados para análise 4 teses e 34 dissertações, e os produtos desta pesquisa resultaram em dados sobre o papel desempenhado pelo coordenador pedagógico nos diferentes níveis de educação e as dificuldades que os CPs enfrentam para realizar seu ofício no cotidiano das escolas. Os autores apontam que

Dentre as pesquisas consultadas, quinze autores destacam algumas causas do porquê de muitos desses coordenadores não conseguirem nortear o sentido pedagógico das suas ações, deixando de valorizar seu papel ao não cumprir suas atribuições de forma reflexiva e, sobretudo, por não tê-las delineadas num projeto de trabalho que leve em conta as peculiaridades da escola onde atuam. Essa ausência de planejamento - somada a eventuais disfunções, má formação, excesso de trabalho sem foco e descompromisso com o trabalho coletivo - causa um impacto negativo na atuação dos coordenadores (MIZIARA; RIBEIRO; BEZERRA, 2014, p. 611).

Com base nas ponderações das autoras, fica evidente que as pesquisas analisadas sugerem a formação continuada como a principal atribuição dos coordenadores pedagógicos, visto que das 38 pesquisas selecionadas, 25 discutem a relevância da função formadora dos CPs, porém, problematizando a insuficiência da atuação dos CPs neste aspecto devido, principalmente, aos "desvios de função" que permeiam o trabalho dos coordenadores, subtraindo-lhes o tempo que poderia estar direcionado à sua função formativa.

De acordo com os autores

Percebe-se que a situação descrita é sintomática na maioria das escolas brasileiras. A discussão teórica ainda é entendida como uma exigência ocasional, mas não constitui elemento catalisador da atuação pedagógica. Dessa maneira, os imperativos burocráticos e rotineiros se tornam obstáculos à dinâmica do trabalho do coordenador. Por consequência, a atuação formadora esvai-se, o que tolhe a retomada crítica do fazer pedagógico. (MIZIARA; RIBEIRO; BEZERRA, 2014, p. 615) 
Os autores concluem que, além de problemas na formação inicial e continuada dos CPs, torna-se necessário repensar as formas de investidura deles à função, pois os dados levantados apontam o concurso público como critério ideal para admissão ao cargo, em detrimento à indicação ou nomeação que ocorre na maioria das redes de ensino.

As pesquisas aqui analisadas evidenciaram que há um crescente nas produções que abordam a coordenação pedagógica e toda a multiplicidade de elementos que compõem a função. De acordo com os apontamentos dos autores, os estudos revelam a ampliação das discussões acerca da identidade do $\mathrm{CP}$ e da sua centralidade na mediação das ações pedagógicas, na promoção do trabalho coletivo e, principalmente, na formação continuada dos professores.

\subsection{Demais produções sobre coordenadores pedagógicos, no período de 2008 a 2018}

Com o propósito de evidenciar o que revelam as pesquisas com relação à formação dosCPs, foram realizadas buscas nos bancos de dados da CAPES e BDTD, no intuito de investigar o que demonstram sobre suas necessidades formativas, e em que medida as propostas e iniciativas de formação continuada a eles direcionadas refletem nas ações pedagógicas por eles desenvolvidas.

Inicialmente, utilizando o descritor "formação do coordenador pedagógico" no título, foram acessadas, no site da BDTD, 55 pesquisas, considerando um recorte temporal de 2008 a 2018, sendo 7 teses e 48 dissertações. O mesmo procedimento foi realizado no site da CAPES, resultando 10 produções, sendo todas dissertações. No intuito de aprofundar as pesquisas, foram realizadas novas buscas com as seguintes variações: "Formação Continuada para os coordenadores pedagógicos"; "Formação Continuada do Coordenador Pedagógico".

As buscas resultaram em 61 produções, aglutinando-se as produções da CAPES e BDTD, sendo 8 teses e 53 Dissertações. Os dados levantados foram organizados no quadro abaixo:

Quadro 1- Produções encontradas de acordo com o descritor utilizado para a busca, de $2008 / 2018$

\begin{tabular}{|c|c|c|c|}
\hline \multirow{2}{*}{ SITE } & \multirow{2}{*}{ DESCRITOR } & \multicolumn{2}{|c|}{ TIPO DE PRODUÇÃO } \\
\hline & & TESE & DISSERTAÇÃO \\
\hline BDTD & Formação Continuada para os coordenadores & 1 & 8 \\
\hline CAPES & pedagógicos & 0 & 2 \\
\hline BDTD & Formação Continuada do Coordenador Pedagógico & 2 & 11 \\
\hline
\end{tabular}




\begin{tabular}{|l|l|r|r|} 
CAPES & 1 & 3 \\
\hline BDTD & & 3 & 17 \\
\cline { 1 - 3 } CAPES & Formação do Coordenador Pedagógico & 1 & 12 \\
\hline Total & & 8 & 53 \\
\hline
\end{tabular}

Fonte: elaborado pelas autoras para esta pesquisa, a partir de dados dos sites da CAPES E BDTD, considerando o período de 2008/2018.

Analisando os títulos das produções, observou-se que tanto se referiam ao coordenador pedagógico enquanto formador, quanto à formação por ele recebida. Então, devido ao grande número de produções foi necessário um recorte de acordo com a intencionalidade desta pesquisa. Desse modo, foram selecionadas as produções que tinham como preocupação discutir a formação dos CPs.

Após esta análise, considerando o recorte temporal de 10 anos, ou seja, de 2008 a 2018, e excluindo-se as produções que figuram em duplicidade nos dois sites de busca, o resultado final foi de 34 produções, sendo 4 teses e 30 dissertações. Iniciaremos as análises pontuando sobre as produções por região do país, conforme representado no gráfico abaixo:

Gráfico 1 - Teses e dissertações mapeadas e organizadas por região

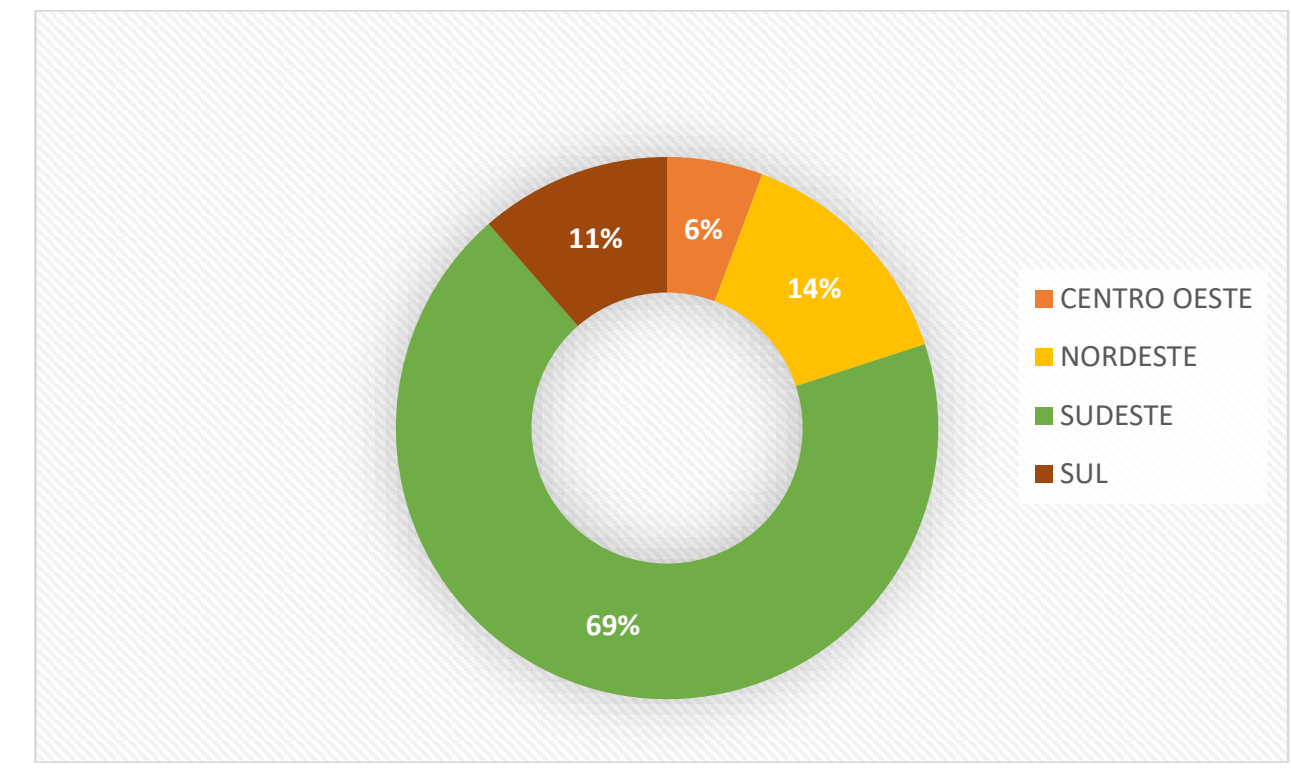

Fonte: Elaborado pelas autoras para a presente pesquisa com base nos dados da CAPES e BDTD

Analisando as produções por região, é possível destacar a preeminência da região Sudeste, visto que concentra $69 \%$ das produções, em sua grande parte desenvolvidas nas instituições privadas. Em análise mais detalhada, considerando as Instituições de Ensino Superior - IES em que as produções estão vinculadas, organizamos o gráfico abaixo: 


\section{OO DEVIR EDUCAÇÃO \\ ISSN: 2526-849X}

Gráfico 2 - Volume das produções por região brasileira de 2008/2018

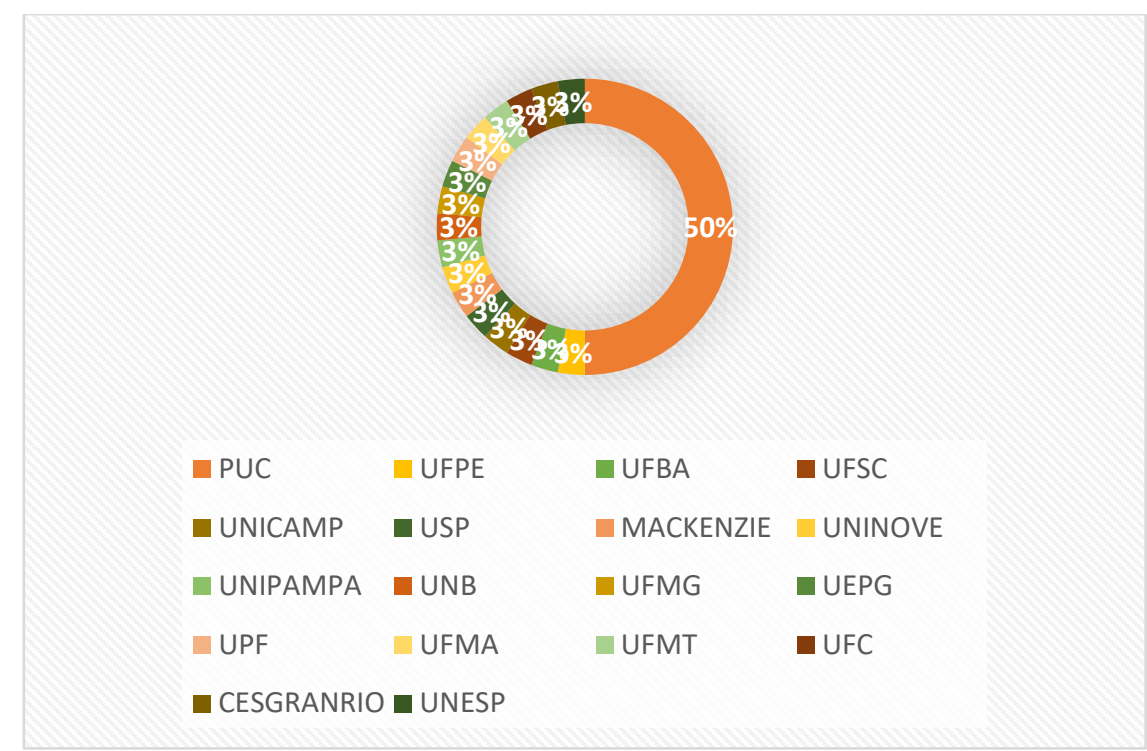

Fonte: Produções de acordo com o banco de dados da CAPES E BDTD, organizados por IES, elaborado pelas autoras para a presente pesquisa

Depreende-se desta análise que a maior concentração de produções se dá no estado de São Paulo, mais especificamente na Pontifícia Universidade Católica de São Paulo - PUC/SP, pois das 34 produções mapeadas, $50 \%$ tem vínculo com esta IES.

Na busca dos motivos do destaque desta produção nesta região, encontramos dados que se justificam, a priori, pela criação do Mestrado Profissional em Educação: Formação de Formadores (FORMEP) cujas atividades tiveram início em agosto de 2013. Em análise da dissertação de Monie Fernandes Pacitti (2017), que figura entre as produções mapeadas para esta pesquisa, corroborou-se à justificativa supracitada, visto que esclarece sobre a ampliação da procura, pelos coordenadores, por formação específica que subsidie a sua atuação.

A investigação de Pacitti (2017), intitulada "Mestrado Profissional em EducaçãoFormação De Formadores (PUC-SP): Contribuições Para Coordenadores Pedagógicos da Rede Municipal de Ensino de São Paulo", tenciona evidenciar as contribuições do mestrado profissional (FORMEP) para o desenvolvimento profissional dos coordenadores pedagógicos que cursaram as três primeiras turmas ofertadas (de 2013 a 2015), no sentido de verificar, principalmente, as aprendizagens mobilizadas no mestrado e como se dá a aplicação destes conhecimentos adquiridos na prática desses coordenadores.

A autora expõe que uma das alternativas encontradas pelos CPs para aperfeiçoar seu desempenho na função tem sido a procura por cursos de formação nas universidades. Além 


\section{OO DEVIR EDUCAÇÃO \\ ISSN: 2526-849X}

disso, os resultados da pesquisa indicam que o mestrado profissional contribui para o desenvolvimento profissional dos CPs, visto que os principais temas discutidos estão em consonância com os desafios por eles enfrentados no exercício da coordenação, com destaque para a formaçao de professores e as relações interpessoais.

Dando continuidade às análises das produções, outro aspecto a ser destacado é a graduação dos pesquisadores, que, na sua grande maioria, atuam ou já atuaram como CPs, referendando a assertiva de Romanowski (2013), que afirma que "o ponto de partida da escolha do objeto a ser investigado vincula-se à prática que o pesquisador realiza". (ROMANOWSKI, 2013, p. 485).

Ressalta-se que, para a investidura na função de $\mathrm{CP}$ em alguns estados a licenciatura em pedagogia é obrigatória. Assim, o gráfico abaixo demonstra a prevalência da licenciatura em pedagogia como formação inicial dos pesquisadores:

Gráfico 3 - Formação inicial dos pesquisadores 2008/2018 de acordo com as pesquisas

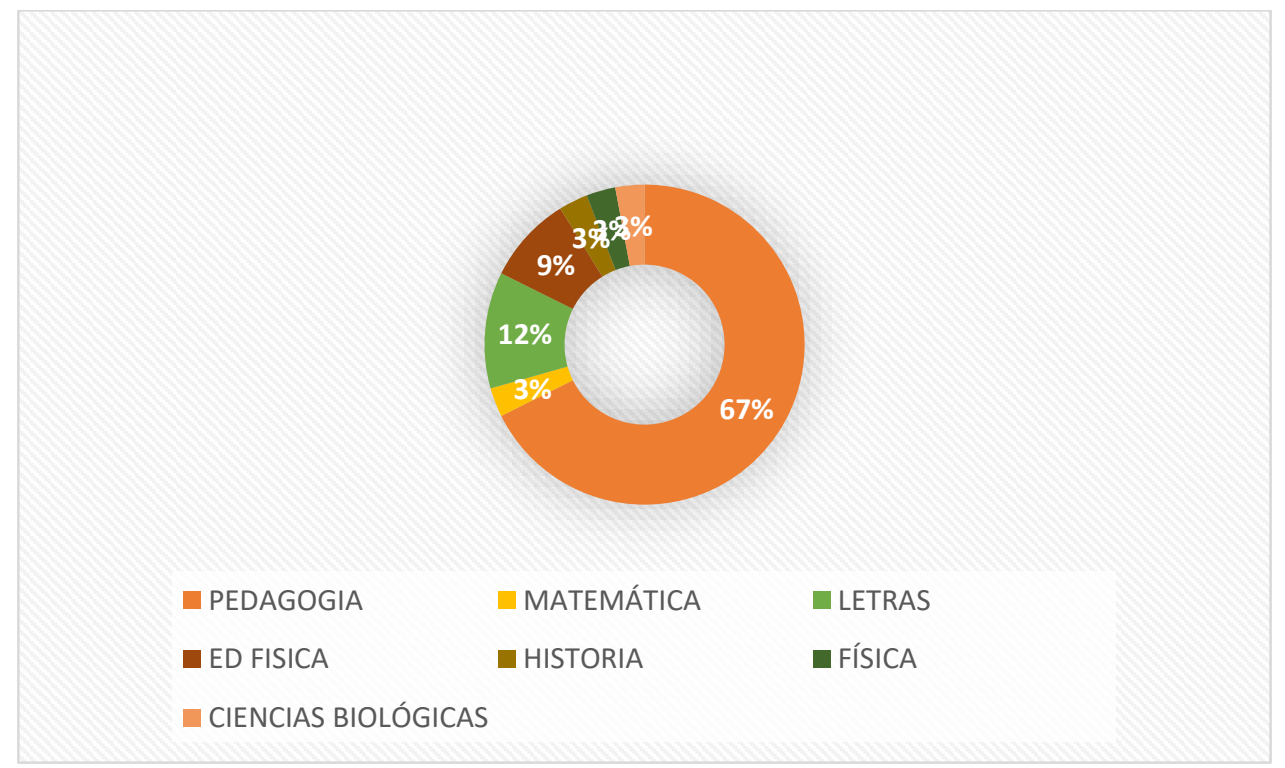

Fonte: elaborado pelas autoras para a presente pesquisa, de acordo com os levantamento no banco de dados da CAPES E BDTD

Uma análise mais detalhada dos dados possibilitou compreender de onde partiam as pesquisas e a que redes de ensino estavam vinculadas as investigações. O gráfico abaixo demonstra a divisão das pesquisas por redes de ensino/instituição pesquisadas:

Gráfico 4 - Objeto de pesquisa dos investigadores por tipo de sistema de ensino

Revista Devir Educação, Lavras, vol.4, n.1, p.26-46 jan./jun., 2020. 


\section{OO DEVIR EDUCAÇÃO \\ ISSN: 2526-849X}

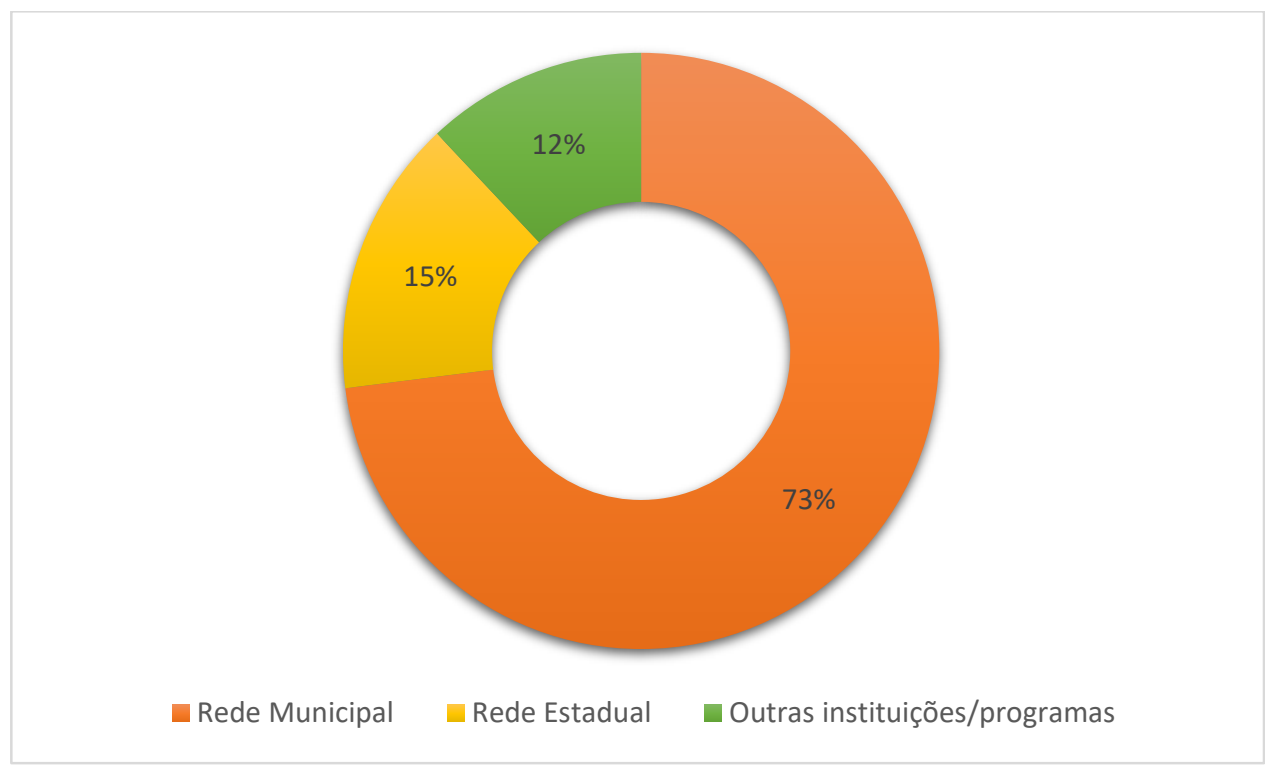

Fonte: elaborado pelas autoras para a presente pesquisa de acordo com os dados mapeados no banco de dados da CAPES E BDTD.

Percebe-se pelo gráfico 4, uma articulação dos dados apresentados, visto que a maioria das pesquisas tem como sujeitos os coordenadores pedagógicos da Educação Infantil e anos iniciais do Ensino Fundamental, etapas da Educação Básica que são ofertadas predominantemente pelas redes municipais de ensino.

Interessou-nos investigar, primeiramente, a origem dos dados analisados e o que evidenciam estas pesquisas acerca da formação do coordenador pedagógico, e, para tal, selecionamos as pesquisas de Ciríaco (2015), que investigou a rede municipal, e Pignataro (2016), que investigou a rede estadual de educação, pois estas utilizaram a análise documental como principal fonte de dados

A pesquisa de Marise Leão Ciríaco (2015), intitulada “A Formação dos Coordenadores Pedagógicos da SEMED Maceió: 2012-2013, buscou analisar o regimento interno da rede municipal de Maceió, os referenciais para a formação de professores e os projetos de formação continuada dos coordenadores nos anos de 2012 e 2013. A pesquisadora aponta para a ausência de parâmetros específicos para o atendimento ao perfil exigido para o $\mathrm{CP}$, bem como a insuficiência de subsídios teórico-metodológicos que possibilitem uma atuação profícua dos professores que desempenham a função de $\mathrm{CP}$, principalmente no que tange à sua atuação enquanto formador.

A partir da análise documental realizada, a autora concluiu que, para atuar de forma adequada, é necessário que o CP receba formação que possibilite a contextualização dos conhecimentos docentes em situações pedagógicas nos momentos formativos das escolas em 


\section{QD DEVIR EDUCAÇÃO \\ ISSN: 2526-849X}

que atuam. Infere, ainda, que nos projetos de formação para CPs, no recorte e contexto utilizado na pesquisa, foi identificada a ausência de ações didático-metodológicas, de natureza integradora, que subsidiem de maneira substancial os CPs enquanto articuladores da formação dos professores, o que levou a autora a defender a necessidade de que sejam repensados os contextos de formação e suas implicações.

Similarmente, a pesquisa de Flavia Viana de Lima Pignataro, (2016), sob o título "Em busca da ilha desconhecida: o Professor Coordenador Pedagógico e a formação continuada no contexto da rede estadual paulista" teve como problematização as atribuições legais do Professor Coordenador Pedagógico $\left(\mathrm{PCP}^{6}\right)$ do Ensino Fundamental do ciclo 1 da rede estadual paulista, bem como a disponibilização e realização de programas de formação ofertados pela Secretaria Estadual de Educação de São Paulo - SEE/SP aos PCPs.

Os objetivos propostos pela autora para a pesquisa foram analisar o papel e atribuições do PCP, tendo como objetos de análise as produções científicas dos bancos de dados da CAPES e BDTD, dos anos 2009 a 2015. De acordo com a autora:

[...] nas últimas décadas tem aumentado a preocupação de diversos estudiosos com questões relativas à formação continuada e a atuação do professor coordenador pedagógico no interior da escola. Além disso, destacamos a necessidade urgente de que os gestores de políticas de organização das rotinas escolares e de formação continuada dirijam seus olhares com mais atenção a esses temas (PIGNATARO, 2016, p. 8).

Outra fonte de análise utilizada pela autora foram os documentos propostos pela SEE/SP, como leis, resoluções e decretos, ou seja, os marcos legais que regulamentam e direcionam o trabalho dos PCPs, com o recorte temporal de 1970 a 2016. A pesquisadora apontou que tais documentos apresentam um caráter gerencialista e pouca clareza, o que acarreta em distorções no entendimento das reais funções e atribuições dos PCPs.

Com base na análise realizada, a autora assinala que ainda que sejam evidentes e significativos os avanços no que se refere à temática, o estudo revelou algumas divergências com relação às ações do estado com relação a formação continuada dos PCPs.

Retomando as análises das produções, com relação às referências teóricas abordadas nas pesquisas selecionadas, 19 trabalhos não as especificaram. Nas pesquisas que apresentaram referenciais, observa-se a predominância por Placco e Almeida (2011, 2012, 2015)

\footnotetext{
${ }^{6}$ Denominação do coordenador pedagógico no estado de São Paulo
}

Revista Devir Educação, Lavras, vol.4, n.1, p.26-46 jan./jun., 2020. 
pesquisadoras de temáticas relacionadas à identidade, funções, atribuições e aspectos da atuação dos CPs, e professoras integrantes do FORMEP.

Devido ao número de pesquisas mapeadas, foram selecionadas três produções, sendo duas dissertações e uma tese, para um estudo mais aprofundado, utilizando como critério de seleção as produções que fizessem referência às propostas de formação em diferentes instituições, considerando-se também que respondessem aos objetivos e a problematização da pesquisa ora apresentada.

Tal é o caso da pesquisa de mestrado de Priscila de Giovani (2013), intitulada "Coordenador pedagógico: contribuições para sua formação", que teve como problema central investigar a importância da formação do CP, aliada à inquietação: em que condições a formação pode ser oferecida para construir na atuação desse gestor? Os objetivos específicos gravitaram em torno do resgate histórico da formação de professores no Brasil, a importância da figura do CP para a formação de professores e em que condições a formação para os CPs acontece.

A investigação, de abordagem qualitativa, foi realizada com 11 coordenadores da rede municipal de Santo André (SP), e teve como critérios de seleção dos participantes o tempo de exercício na coordenação pedagógica, formando um grupo misto, composto por CPs com menos de 5 anos de exercício da coordenação e também com mais de 5 anos, no intuito de articular o aspecto "experiência" com os reflexos da formação continuada específica para o coordenador ao longo do tempo na função. As entrevistas foram categorizadas em três eixos, tendo como foco a problematização acerca da formação inicial dos CPs, as ações formativas por eles desenvolvidas junto aos professores, bem como o significado que atribuem à formação específica para os CPs.

De acordo com a autora, a formação dos CPs contribui para o exercício de sua função, desde que sejam observados os conteúdos e estratégias formativas que garantam a aplicabilidade efetiva nas suas ações enquanto CP. Giovani (2013) assegura, à luz dos referenciais teóricos e dos resultados da pesquisa, que

[...] é possível observar que o coordenador pedagógico recebe poucas contribuições na sua formação inicial para cumprir sua principal função na unidade escolar: a formação de professores, necessitando de outros momentos formativos ao longo de sua atuação profissional (GIOVANI, 2013, p. 74).

A partir do levantamento bibliográfico e dos dados analisados, a formação do CP deve conter algumas características consideradas por Giovani (2013, p. 115-116) como essenciais, 


\section{OO DEVIR EDUCAÇÃO \\ ISSN: 2526-849X}

tais como: ser contínua e concomitante ao exercício da função; possibilitar reflexão da prática e a articulação entre conteúdos disciplinares e didáticos; favorecer a homologia de processos; conteúdos de formação alinhados com as e necessidades formativas dos $\mathrm{CP}$; promover e incentivar estudos complementares. Além disso, é imprescindível que os formadores conheçam as especificidades do grupo, no sentido de que suas necessidades e interesses sejam contemplados.

A outra pesquisa selecionada trata-se de uma dissertação de mestrado intitulada: "Uma proposta de Formação em serviço: Professores na função de Coordenadores Pedagógicos na Rede Pública”, de Elida Aparecida Tardeli (2014).

O estudo teve como objeto a formação em serviço dos CPs da rede pública estadual de SP. A pesquisa se deu por meio de proposta de intervenção, sendo que as ações foram desenvolvidas em encontros semanais, durantes 6 meses, e contemplando 24 professores recém designados à função de CPs, no intuito de revelar as potencialidades e necessidades de professores no início do exercício desta função. De acordo com a autora

A ideia é propor uma intervenção na organização de um novo grupo de formação, disponibilizar espaços e momentos especiais de trocas no grupo específico de Coordenadores iniciantes, com necessidades mútuas, a fim de que o profissional se reconheça e possam com autonomia, apoiados pelo trabalho coletivo e colaborativo receber suporte permanente de qualificação para o desempenho da nova função (TARDELI, 2014, p. 24).

A proposta foi organizada de forma a superar os processos em que todos os coordenadores, independentemente do tempo de atuação na função, são vistos como iguais nas suas necessidades e dificuldades. Todos os participantes da pesquisa apresentaram acima de 6 anos de exercício da docência, porém, a sua grande maioria estava atuando como CP por menos de um ano. Tardeli (2014) elenca como pontos relevantes da formação desenvolvida as trocas de experiências do grupo, a ampliação do conhecimento da realidade a qual estão inseridos e as possibilidades de uma melhor organização do trabalho pedagógico.

Como última produção selecionada está a tese de Rinalda Bezerra Carlos (2013), que realizou "Um estudo sobre a formação continuada do Coordenador Pedagógico desenvolvida pelo CEFAPRO de Cáceres/MT”, objetivando investigar em que medida essa formação continuada contribui para a formação do CP.

Carlos (2013) investigou os encontros do Projeto Sala de Gestores, ofertado pela rede estadual via Centro de Formação e Atualização dos profissionais da Educação- CEFAPRO, do

Revista Devir Educação, Lavras, vol.4, n.1, p.26-46 jan./jun., 2020. 


\section{QO DEVIR EDUCAÇÃO \\ ISSN: 2526-849X}

Estado de Mato Grosso. No intuito de aprofundar a investigação, a autora também visitou as escolas e entrevistou os gestores que participam desta formação. Ficou evidente na fala dos gestores que a formação era ofertada a todos os gestores em um único grupo, sem atendimento específico aos CPs. Além disso, a autora problematiza que a formação não partia das necessidades dos cursistas e sim de eixos determinados pela SEDUC/MT.

Por outro lado, não havia uma agenda de formação, e os gestores tinham conhecimento das temáticas que seriam abordadas somente no próprio encontro. Por esse motivo, não ocorriam estudos prévios por parte dos cursistas que possibilitassem análise e participação efetiva nas discussões propostas. De acordo com a autora

Em relação às temáticas trabalhadas nessa formação, os gestores manifestaram que, em geral, elas não condizem com as necessidades vivenciadas pelas escolas e que, nos encontros de formação, não se discutem estratégias específicas para serem desenvolvidas nas escolas, voltadas à superação das dificuldades (CARLOS, 2013, p. 19, grifo nosso).

A autora avalia como positivo o fato de o Estado de Mato Grosso contar com uma Política de Formação Continuada que contemple todos os profissionais da educação, porém, afirma que as estratégias formativas adotadas pelo CEFAPRO de Cáceres evidenciam não contribuir de maneira eficaz para o desenvolvimento das funções de maneira a contemplar as exigências das Políticas Públicas do Estado do Mato Grosso, tampouco as especificidades da função do coordenador pedagógico.

Pode-se concluir, diante dos dados expostos, que a formação dos coordenadores pedagógicos ainda permanece como um entrave do desenvolvimento profissional destes sujeitos e, portanto, necessita de um olhar mais criterioso por parte das instituições de ensino, quer sejam das redes municipal ou estadual, visto que as propostas de formação e os resultados que as pesquisas evidenciam apresentam convergências no que se refere ao não atendimento das suas necessidades formativas.

\section{Considerações Finais}

O objetivo do texto ora apresentado foi de trazer ao centro da discussão as necessidades formativas dos CPs que figuram nas pesquisas sobre a formação dos CPs em âmbito nacional, 


\section{QD DEVIR EDUCAÇÃO \\ ISSN: 2526-849X}

bem como de que maneira as propostas e iniciativas de formação são formuladas no sentido de atender essas necessidades. Pode-se concluir que as informações levantadas nas produções mapeadas produziram dados que permitiram analisar outras questões adjacentes a esta pesquisa, visto que para além da formação em serviço, ofertadas redes de ensino em que atuam os CPs, abordaram aspectos da regulamentação da função e dos desafios que a permeiam.

Os produtos desta pesquisa revelaram, com maior ênfase, aspectos sobre a elaboração de propostas formativas organizadas pelas redes/instituições, bem como a grande dificuldade que os CPs enfrentam em se identificar com estas propostas, devido às inconsistências tanto da parte dos ofertantes, quanto dos próprios cursistas. Em que pese a importância do CP como formador, presente na maioria das pesquisas, ainda não se percebe o reconhecimento dos CPs como agentes da própria formação, restringindo-se à tarefa de aprender o ofício para mediar a formação docente.

A maioria das produções apresentaram marcos históricos e legais acerca da função e da atuação do $\mathrm{CP}$, todavia é marcante o descompasso entre as exigências legais e sua atuação, devido à multiplicidade de atribuições. Outro aspecto relevante que se evidencia nas pesquisas são os dilemas dos CPs no que tange à constituição de sua identidade profissional, devido à falta de reconhecimento da centralidade de sua função, bem como da inexistência de um perfil especifico para a investidura na função.

Na direção da formação de $\mathrm{CP}$, as produções aqui referidas e a análise temática dos estudos realizados pelos pesquisadores remetem-nos à clarificação de suas necessidades formativas, e resultam em subsídios para o aprofundamento da discussão sobre os aspectos da sua formação e atuação. Entretanto, importa salientar que a investigação possibilitou depreender que, embora que as pesquisas sobre a temática tenham avançado consideravelmente nos últimos anos, ainda são incipientes as iniciativas de formaçao continuada que considerem as necessidades formativas dos coordenadores pedagógicos como balizadoras da sua formulação e realização, favorecendo assim, o distanciamento entre o proposto nas pesquisas e o que tem se observado na atuação dos coordenadores.

\section{Referências}

ALMEIDA, Laurinda Ramalho. A dimensão relacional no processo de formação docente: uma abordagem possível. In: BRUNO, Eliane Bambini Gorgueira; ALMEIDA, Laurinda Ramalho; CHRISTOV, Luiza Helena da Silva. (Org.). O coordenador pedagógico e a formação docente. São Paulo: Loyola, 2000. 


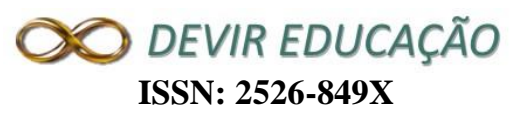

ALVES, Cristina Nacif. O sentido dos argumentos para a formação de coordenadores pedagógicos: caminhos para a aproximação entre teoria e prática. Rio de Janeiro: UFRJ, 2007. 146f. Dissertação (mestrado em Educação). Universidade Federal do Rio de Janeiro, 2007.

ANDRÉ, Marli Elisa Dalmazo Afonso. Pesquisa em Educação: questões de teoria e método. Ed. Tecnol., Belo Horizonte, v.10, n.1, p. 29-35, jan./jun. 2005.

ANDRÉ, Marli Elisa Dalmazo Afonso. VIEIRA, Marili M. da Silva. O coordenador pedagógico e a questão dos saberes. In: ALMEIDA, Laurinda Ramalho; PLACCO, Vera Maria Nigro de Souza. $\mathbf{O}$ coordenador pedagógico e questões da contemporaneidade. São Paulo: Loyola, 2006.

BRUNO, Eliane Bambini Gorgueira. O trabalho coletivo como espaço da formação. In: O coordenador pedagógico e a educação continuada. PLACCO, Vera Maria Nigro de Souza; ALMEIDA, Laurinda R. de (Org.) - São Paulo: Edições Loyola, 1998.

BDTD. Biblioteca Digital Brasileira de Teses e Dissertações do Ministério de Ciência e Tecnologia (MCT). Disponível em: http://bdtd.ibict.br/vufind/ Acesso em: 18. Maio.2019

CAPES. Coordenação de Aperfeiçoamento de Pessoal de Nível Superior do Ministério da Educação (CAPES/MEC). Banco de dissertação e teses. Disponível em: http://www.capes.gov.br. Acesso em: 18. Maio.2019

CARLOS, Rinalda Bezerra. Um estudo sobre a formação continuada do Coordenador Pedagógico desenvolvida pelo CEFAPRO de Cáceres/MT. São Paulo, SP: PUC, 2013. 180 f. Tese (Doutorado em Educação) - Pontifícia Universidade Católica de São Paulo, 2013.

CIRIACO, Marise Leão. A formação de Coordenadores Pedagógicos da SEMED Maceió: 2012-2013. São Paulo, SP: PUC, 2015. 115 f. Dissertação (Mestrado em Educação) - Pontifícia Universidade Católica de São Paulo, 2018.

CUNHA, Renata Barrichelo; PRADO, Guilherme do Val Toledo. Sobre importâncias: a coordenação e a conformação na escola. In: PLACCO, Vera Maria Nigro de Souza Almeida, ALMEIDA, Laurinda Ramalho. (Org.). O coordenador pedagógico e os desafios da Educação. São Paulo: Loyola, 2008.

FERREIRA, Norma Sandra de Almeida. As pesquisas denominadas estados da arte. Educação \& Sociedade. Campinas, ano 23, n. 79, p. 257-72, ago. 2002.

GARCIA, G. Coordenador pedagógico: dilemas na busca por uma formação de si e dos outros. 2016. 81 f. Dissertação (Mestrado em Educação) - Universidade de Passo Fundo, Passo Fundo, RS, 2016.

GEGLIO, Paulo Cesar. Análise temática das sobre o coordenador pedagógico no Brasil. Revista Eletrônica Pesquiseduca v.2, n.4, jul.-dez.-2010 
GIOVANI, Priscila de. Coordenador Pedagógico: contribuições para sua formação. São Paulo, SP: PUC, 2013. 136 f. Dissertação (Mestrado em Educação) - Pontifícia Universidade Católica de São Paulo, 2013.

MATE, Cecilia Hanna. Qual a identidade do professor-coordenador pedagógico? In: O coordenador pedagógico e a educação continuada. PLACCO, Vera Maria Nigro de Souza; ALMEIDA, Laurinda R. de (Org.) - São Paulo: Edições Loyola, 1998.

MIZIARA; Leni Aparecida Souto; RIBEIRO, Ricardo; BEZERRA, Giovani Ferreira. O que revelam as pesquisas sobre a atuação do coordenador pedagógico. Revista Brasileira de Estudos Pedagógicos. (Online), Brasília, v. 95, n. 241, p. 609-635, set./dez. 2014.

ORSOLON, L. A. M. O coordenador/formador como um dos agentes de transformação da/na escola. In: ALMEIDA, Laurinda Ramalho; PLACCO, Vera Maria Nigro de Souza (Org.). O coordenador pedagógico e o espaço da mudança. 2. ed. São Paulo: Loyola, 2002, p.17-26.

PACITTI, Monie Fernandes. Mestrado Profissional em Educação - Formação de Formadores (PUC/SP): contribuições para Coordenadores Pedagógicos da Rede Municipal de Ensino de São Paulo. São Paulo, SP: PUC, 2017. 136 f. Dissertação (Mestrado em Educação) - Pontifícia Universidade Católica de São Paulo, 2017.

PIGNATARO, Flávia Viana de Lima. Em busca da ilha desconhecida: o professor coordenador pedagógico e a formação continuada no contexto da Rede Estadual Paulista. Presidente Prudente, SP: UNESP, 2016. Dissertação (Mestrado em Educação) -Universidade Estadual Paulista, Universidade Estadual Paulista “Júlio de Mesquita Filho, 2016.

PLACCO, Vera Maria Nigro de Souza. Formação e Prática do educador e do orientador: confrontos e questionamentos. Campinas: Papirus, 1994.

PLACCO, Vera Maria Nigro de Souza. SOUZA, Vera Lúcia Trevisan. Desafios ao coordenador pedagógico no trabalho coletivo da escola: intervenção ou prevenção? In: PLACCO, Vera Maria Nigro de Souza; ALMEIDA, Laurinda Ramalho (Org.) O coordenador pedagógico e os desafio da Educação. São Paulo: Loyola, 2008.

PLACCO, Vera Maria Nigro de Souza. SOUZA, Vera Lúcia Trevisan. Diferentes aprendizagens do coordenador pedagógico. In: ALMEIDA, Laurinda Ramalho, PLACCO, Vera Maria Nigro de Souza. (Org.). O coordenador pedagógico e o atendimento à diversidade. São Paulo: Loyola, 2010.

PLACCO, Vera Maria de Souza, ALMEIDA, Laurinda Ramalho, SOUZA, Vera Lúcia Trevisan. Relatório O Coordenador Pedagógico e a Formação de Professores: intenções, tensões e contradições. Disponível em: <http://www.fvc.org.br/estudos-epesquisas/2010/perfil-coordenadorespedagogicos- 605038.shtml.> Acesso em 02. Mai. 2019

PLACCO, Vera Maria N. de Souza; SOUZA, Vera Lúcia Trevisan de. ALMEIDA, Laurinda Ramalho de. $\mathrm{O}$ coordenador pedagógico $(\mathrm{CP})$ e a formação de professores: intenções, tensões e contradições. Estudos \& Pesquisas Educacionais - Fundação Victor Civita, 2011. 


\section{QD DEVIR EDUCAÇÃO \\ ISSN: 2526-849X}

PLACCO, Vera Maria Nigro de Souza; SOUZA, Vera Lúcia Trevisan; ALMEIDA, Laurinda Ramalho de. O coordenador pedagógico: aportes à proposição de políticas públicas. In: Cadernos de Pesquisa v. 2 n.147, p. 754-771. Set/dez. 2012.

PLACCO, Vera M.N de S.; ALMEIDA, Laurinda R. de; SOUZA, Vera L.T. Retrato do coordenador pedagógico brasileiro: nuanças das funções articuladoras e transformadoras. In: $\mathbf{O}$ coordenador pedagógico no espaço escolar: articulador, formador e transformador. PLACCO, Vera M.N de S.; ALMEIDA, Laurinda R. de (Org.) - São Paulo: Edições Loyola, 2015.

ROMANOWSKI, Joana Paulina; ENS, Romilda Teodora. As pesquisas denominadas do tipo "Estado da arte" em educação. Revista Diálogo Educacional. Curitiba, vol. 6, n. 19, p. 37-50, Set/Dez. 2006. Disponível

em: https://periodicos.pucpr.br/index.php/dialogoeducacional/article/view/24176. Acesso em 23.ago. 2019

ROMANOWSKI, Joana Paulin. Tendências da pesquisa em formação de professores. Atos de pesquisa em educação, v.8, n. 2, p. 479-499, mai./ago. 2013 Disponível em: https://proxy.furb.br/ojs/index.php/atosdepesquisa/article/view/3711. Acesso em 23.ago.2019

TARDELI, Élida Aparecida. Uma proposta de formação em serviço: professores na função de coordenadores pedagógicos na rede pública. São Paulo, SP: UNINOVE, 2014.150 f. Dissertação (Mestrado em Gestão e Práticas Educacionais) - Universidade Nove de Julho, 2014.

ZABALZA, Miguel Angel. Planificação e desenvolvimento curricular na escola. Lisboa: edições ASA, 1994

Recebido em: 03/09/2019.

Aprovado em: 10/12/2019.

Revista Devir Educação, Lavras, vol.4, n.1, p.26-46 jan./jun., 2020. 